\title{
Hazagora: will you survive the next disaster? - A serious game to raise awareness about geohazards and disaster risk reduction
}

\author{
S. Mossoux ${ }^{1,2}$, A. Delcamp ${ }^{1}$, S. Poppe ${ }^{1}$, C. Michellier ${ }^{3}$, F. Canters ${ }^{2}$, and M. Kervyn ${ }^{1}$ \\ ${ }^{1}$ Physical Geography, Department of Geography, Earth System Science, Vrije Universiteit Brussel, Pleinlaan 2, \\ 1050 Brussels, Belgium \\ ${ }^{2}$ Cartography and GIS Research Group, Department of Geography, Vrije Universiteit Brussel, Pleinlaan 2, \\ 1050 Brussels, Belgium \\ ${ }^{3}$ Natural Hazards Service, Department of Geology, Royal Museum for Central Africa and ANAGEO/IGEAT Université Libre \\ de Bruxelles, 1050 Brussels, Belgium \\ Correspondence to: S. Mossoux (smossoux@vub.ac.be)
}

Received: 13 July 2015 - Published in Nat. Hazards Earth Syst. Sci. Discuss.: 1 September 2015

Revised: 17 November 2015 - Accepted: 6 December 2015 - Published: 18 January 2016

\begin{abstract}
Natural disasters are too often presented as resulting from extreme natural phenomena affecting helpless populations, with people being insufficiently aware of the factors leading to disasters and of the existing strategies to mitigate their impacts. We developed a board game aimed at raising awareness about geohazards and disaster risk reduction strategies. The target groups are (1) secondary school students and citizens and (2) scientists and stakeholders involved in risk management activities. For the first group, the aim is to induce a better understanding of the geohazards and disasters they are confronted with in the media or in their daily lives; for the second, the objective is to generate discussion about risk management strategies. The game was tested with students in Belgium and with citizens, earth scientists, and risk managers in several African countries. Based on analysis of the most common game strategies observed, the players' reactions during the game, and their answers to a short questionnaire, we analyzed the main learning outcomes conveyed by this game. The game Hazagora appears to positively enhance the players' insights into processes involved in disasters. As such, the game is an effective, fun learning tool to introduce participants to the concepts of geohazards and disasters and to generate discussion.
\end{abstract}

\section{Introduction}

Disasters causing havoc are repeatedly making the media headlines. However, the media generally focus on the natural component of disasters, giving less attention to the human factors shaping the outcomes of the event. Since the turn of the millennium, the scientific community and international institutions recognize that outcomes of disasters are mostly controlled by political, economic, social, physical, environmental, and stochastic processes rather than by the event intensity (United Nations, 2015; Wisner et al., 2003). Exposure and vulnerability to hazards is not the same for all humans (Wisner et al., 2003). The uneven burden of disaster victims in developing countries, especially in Asia and Africa (GuhaSapir et al., 2014), highlights that the political and socioeconomic context of natural hazard events is an essential factor contributing to the impact of disasters. This factor controls the capacity of the authorities to mitigate impacts based on scientific risk assessment and preparedness actions (United Nations, 2005). These same factors also influence the rights one individual or community has to access land and natural resources, wealth, information, and health (Wisner et al., 2003). Therefore, nowadays disaster reduction strategies focus not only on understanding and reducing hazards but also on increasing the resilience of societies (Smith, 2013; United Nations, 2015).

The conceptual understanding of the combination of factors that lead to catastrophes and the strategies to address 
them is not widely represented by the media and in layman discussions, and it is not always well understood by risk management actors. With that perspective, we present a new serious game that was created with the objective of (1) providing key scientific information about the mechanisms of geohazards, their intensity, spatial extent, and impacts on infrastructures, natural resources, and livelihoods; (2) highlighting the role played by the livelihood and the access to natural resources of families and communities in controlling their vulnerability profile; (3) triggering discussions on strategies that can be implemented to develop a resilient society able to withstand, and to cope with, the impacts of geological disasters. The game was designed to be accessible to a large audience of different age, culture, educational background, and experience.

Serious games are designed to support learning and raise awareness of important issues (Boyle et al., 2014; Pereira et al., 2014). Their main purpose is not entertainment but to use the potential of games to get people engaged and motivated in order to transfer knowledge (Susi et al., 2007). Indeed, the traditional learning cognitive approaches where people only think, analyze, comprehend, and learn by heart without trying, touching, and exploring are increasingly being considered as limited and restrictive (Dieleman and Huisingh, 2006). According to Montessori (1966) and Kolb (1984), the experiential approach is essential in the learning process. To learn, new concepts have to be exposed and people also need to be engaged, motivated, surprised, and challenged (Pereira et al., 2014; Turkay and Adinolf, 2012). Games have a positive contribution to the learning process because they are heuristic. The players can experience complex situations illustrated visually and test new strategies without having to deal with the real consequences of their decisions (Castella et al., 2005; Dieleman and Huisingh, 2006; Lamarque et al., 2013; Souchère et al., 2010; Susi et al., 2007). The fun environment induced by the game reduces anxiety and facilitates debate among people who are otherwise not always brought together. They can share knowledge, make collective decisions, and explore new strategies (Castella et al., 2005; Dieleman and Huisingh, 2006; Lamarque et al., 2013; Souchère et al., 2010; Susi et al., 2007). A game also helps the players to more easily link different processes that the game wants to illustrate (Pereira et al., 2014; Souchère et al., 2010). A game facilitates the development of new personal and social skills and the learning process of new concepts (Castella et al., 2005; Pereira et al., 2014; Susi et al., 2007).

Regarding these characteristics, gaming, as a learning approach, seems particularly relevant in the context of understanding the challenges and complexities involved in coping with natural disasters and increasing resilience. For that reason, we decided to develop Hazagora.

In this paper, we first present the structure of the Hazagora game. Second, we explain how the game was tested on different target groups in Belgium and several African countries. Third, the results of these tests are presented, including the players' contrasted strategies, the impact of the game on improving their understanding of geological disasters, and their opinions on the game. Finally we discuss the elements influencing the development of new strategies during a game session, the fun aspect of Hazagora, and its usefulness as a serious game in raising awareness about the components of the disasters and generating discussion about disaster risk reduction (DRR) strategies, as well as the limitations and prospects of the approach.

Hazagora is a non-commercial game that is available upon request.

\section{The game: objectives, setup, and game rules}

\subsection{Game objective}

The objective of the game Hazagora: will you survive the next disaster? is to develop a resilient community in the face of periodic geological hazards. The game is based on the hypotheses that (1) a resilient community is one that is able to resist, adapt to, and recover from the impacts of geohazardous phenomenon, through the implementation of individual or cooperative mitigation strategies, in a timely and efficient manner (UN/ISDR, 2007); (2) the outcomes of a disaster result from the complex combination of factors including the intensity and the spatial distribution of natural events, the access-to-resources profile of households associated with their livelihood and their settlement location, and finally the capacity of a community to implement preparedness, mitigation, and adaptation risk reduction strategies (UN/ISDR, n.d.).

\subsection{Game setup}

Keeping in mind that the game is a simplification of real life, Hazagora is a board game that displays a volcanic island divided into different land cover areas (Fig. 1a). The central part is occupied by a volcano, surrounded by a forest and by agricultural lands down to the coastal area. Wells and markets, providing water and food, respectively, are scattered across the island. Potential locations where players can develop their family settlements and road networks are drawn on the board game. The board game is divided into different sectors which represent areas that can be affected by a geohazard.

The game can be played with 5 to 10 players, at least 15 years of age. It is led by a game master who follows instructions provided in the Hazagora guidelines. During the game, the players embody one of five characters, each represented by a specific livelihood and color (Fig. 1b): the mayor (red), the fisherman (blue), the lumberjack (green), the farmer (yellow), and the tour guide (black). The livelihood profile of each character limits the potential location of its settlements (e.g., the fisherman is bound to live close to the coastline) and controls its income. In the beginning of the game, players are 
(a)

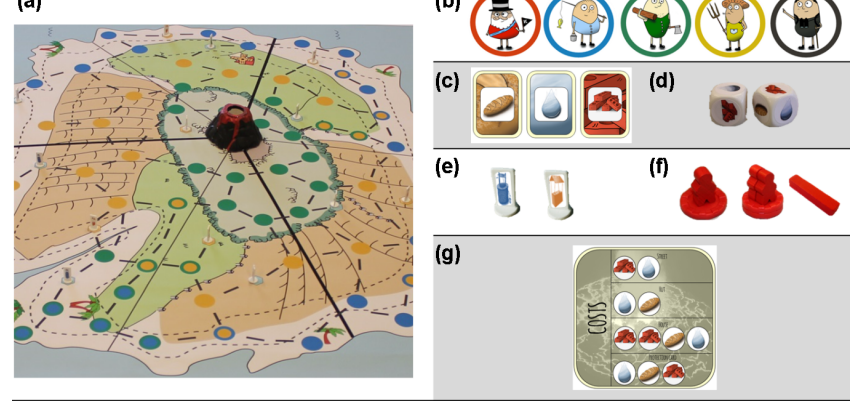

Figure 1. Setup of the game: (a) board game; (b) character cards with from left to right: the mayor, the fisherman, the lumberjack, the farmer and the tour guide; (c) resource cards: bread, water and bricks; (d) resource dice; (e) water well and food market; (f) hut (one chip with one family), house (two chips with two families), and road; (g) cost information card for building new streets, huts, and houses and buying protection cards.

informed of the presence on the board game of water wells, food markets, and sectors dividing the island into different zones that can be potentially affected by hazardous phenomena. No information is given initially about their utility in the game but the players will discover their importance throughout the game. Players are able, in the beginning, to place two families and two roads on the island. This defines the two initial locations from where each character will be allowed to expand from.

\subsection{Playing the game}

Life on the island unfolds in years. A year corresponds to a round table during which players receive an income which can be used to (1) support their families' basic needs and (2) make investments. Each game year, the characters receive a specific income related to their livelihood and multiplied by their number of living families. That income is represented by different resource cards: bread, water, and bricks (Fig. 1c). Two additional resources, representing the variable part of the income, are obtained each year by rolling dice (Fig. 1d). To survive a year, each family has to be sheltered in a hut, a house, or a temporary tent, and its basic needs of food and water have to be met (i.e., one bread and one water per family). The player feeds and gives water to his families by giving the corresponding resource cards back to the game master. Alternatively, the families that are connected by a road to a water well or a food market (Fig. 1e) freely benefit from these resources and thus conserve their resource cards (Fig. 2). Once the basic needs (food, water, and shelter) are met, the rest of the income can be invested to further develop the character's families. Huts, houses, and roads can be built to expand only from the two initial settlements of each character (Fig. 1f). Development of these new infrastructures is spatially constrained for each player to the zones corresponding to his livelihood profile. These locations are marked on

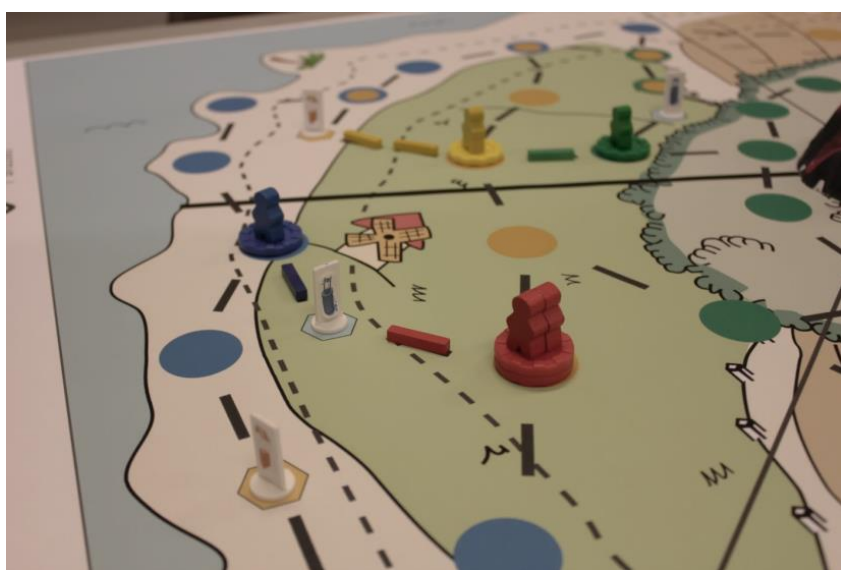

Figure 2. Huts (one family: blue) and a house (two families: red) with road access to a water well. Both yellow and green huts of the background access a food market through the joined road network. This allows these families free access to these resources.

the board game using the color assigned to each (Fig. 1a). No color is assigned to the mayor and the tour guide because no land cover is related to their livelihood. Both characters can live wherever they want on the island. Each time a player establishes a new hut or a new house, he simulates the settlement of one or two additional families, respectively, on the island. The costs of infrastructure are defined by a certain amount and type of resources (Fig. 1g).

\subsection{Occurrence of geohazardous events}

Geological hazardous events (i.e., earthquake, tsunami, lava flow, ash fall) occur on the island at variable time intervals. Each time interval is randomly defined by the game master but is not communicated to the players. Through an alarm, the players are informed of the occurrence of a hazardous phenomenon. Several geohazardous events in 1 year are possible. A probabilistic tree allows random selection of the type and intensity of the geohazard that will occur (Fig.3a). The intensity of hazardous phenomena is defined by an arbitrary three-level scale for earthquake, tsunami, and ash fallout, which corresponds to an increasing spatial extent and/or range of damage. This is not the case for a lava flow which has just one level of destruction (total destruction). The players then watch a video clip, with commentary provided by the game master, which illustrates the hazardous event impacts based on recent disasters. Based on the video clip and their knowledge, the players are invited to explain the mechanisms of hazards and to assess, depending on its intensity, its potential impacts on the elements present on the board game, the available natural resources, and the income of the different characters. An impact table helps them to represent schematically those impacts depending on different intensities (Fig. 4). As already mentioned, the spatial extent of each hazardous event is also defined, based on its nature and its 
(a)

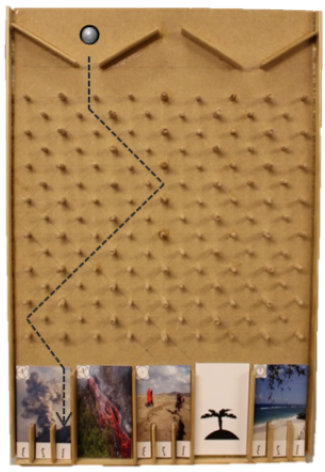

(b)

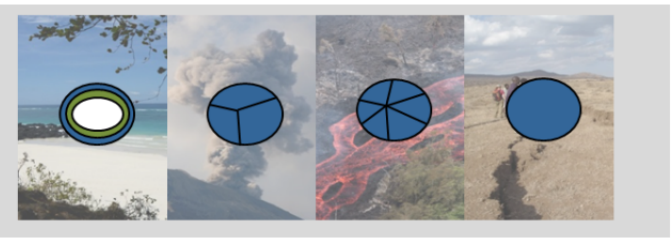

(c)

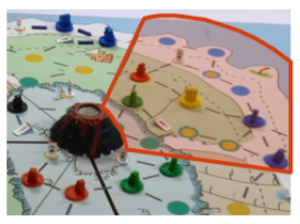

Before (f)

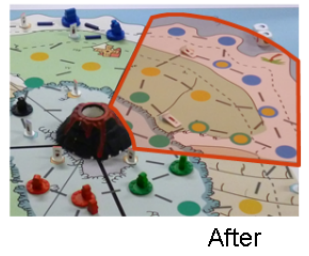

(d)

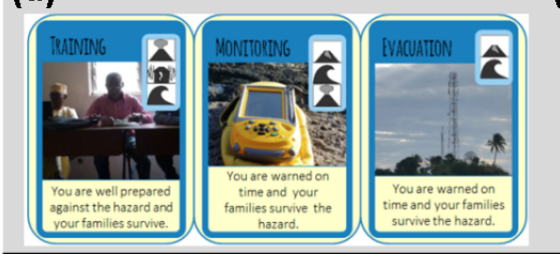

(e)

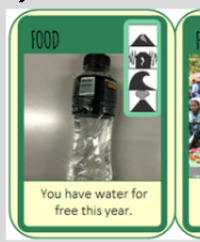

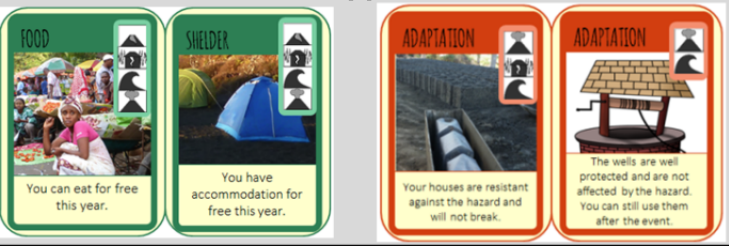

Figure 3. Defining the hazardous event: (a) probability tree; (b) sectors defining potential zones that can be affected from the right to the left by tsunami, ash fall, lava flow, and earthquake on the island; (c) impact of a lava flow on the board game; (d) mitigation.

intensity (Fig. 3b). For example, a tsunami of small intensity will only impact the huts located close to the coast. With larger tsunami intensity, impacts will occur at a larger distance inland and will cause more damage: huts will be destroyed and people living in these huts will be killed, water wells will be contaminated, and the fisherman will lose his income. The fallout from a volcanic plume will impact only one sector of the island due to wind direction controlling its dispersion. Fallout will cause pollution of the water wells and will potentially lead to the loss of income of the farmer and the lumberjack characters when ash fall affects the crops and the vegetation. With a high intensity ash fall, huts collapse due to ash loading on the roof and may kill the people living in these huts. After discussion, the defined impacts related to the hazardous event are implemented on the board game by removing the destroyed elements (i.e., huts, houses, roads), the killed families, by making the contaminated resources inaccessible (i.e., water wells, food markets) and by providing no income to the affected families in the following year (Fig. 3c). In this way, players virtually experience the impacts of the hazardous events through their character and they are directly confronted with the implications of decisions made during the game.

\subsection{Protective actions and community strategies}

In order to reduce the impact of geohazards, each player has the opportunity to acquire "protective actions" which are categorized as mitigation (Fig. 3d), preparedness (Fig. 3e), and adaptation cards (Fig. 3f). Mitigation cards consist of aware-
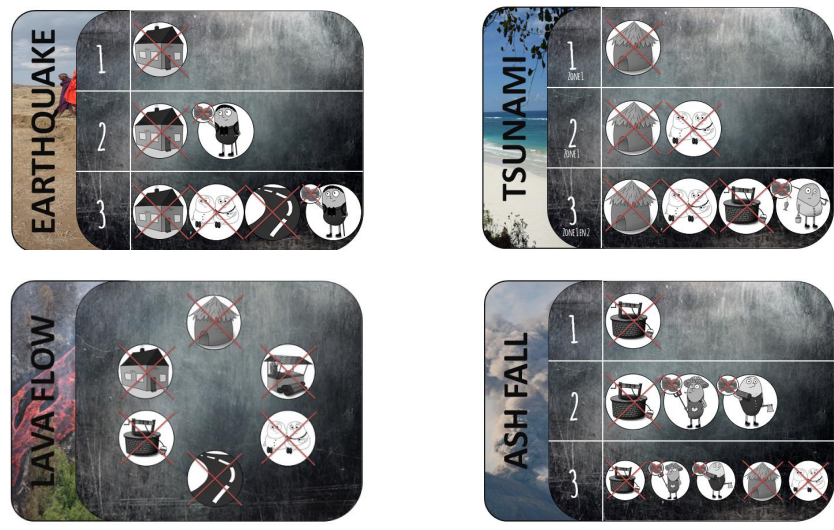

Figure 4. Potential hazardous event impacts when players are not protected. Impacts will be different for different hazardous phenomena intensities. A cross over an infrastructure means it is destroyed within the affected zone. A cross over a family indicates that the families living in the affected zone will not survive the hazardous event. Characters with a small cross suffer a loss of income for 1 year.

ness raising actions, monitoring, and warning systems which enable people to recognize the upcoming hazardous event and evacuate on time. The impacts on infrastructures are still incurred but lives are saved. This is only valid for hazards that may somehow be forecast with a proper monitoring system. Earthquakes are therefore excluded. Preparedness cards consist of stockpiling essential resources, such as water, food, or tents, in order to meet basic needs after being impacted by 
Table 1. Game session information.

\begin{tabular}{llll}
\hline Country & $\begin{array}{l}\text { Number of } \\
\text { game sessions }\end{array}$ & $\begin{array}{l}\text { Number of } \\
\text { participants }\end{array}$ & Participant's profile \\
\hline Belgium, Brussels & 4 & 21 & Secondary (16-18 years) and university students \\
Comoros Islands, Moroni & 3 & 22 & University students, citizens, and stakeholders \\
DRC, Bukavu & 1 & 14 & University students \\
Tanzania, Dodoma & 2 & 18 & Earth scientists and risk managers \\
\hline
\end{tabular}

a hazardous phenomenon. Finally the adaptation cards allow the players to reinforce and protect infrastructure against the impacts of an earthquake, tsunami, or ash fallout.

Players can acquire protection cards individually, but they can also decide to take actions as a community. Individual protection cards require few resources but to be ready to face the various impacts of the different hazardous events, a player has to buy several of them. Moreover, individual protection cards can only be used by the owner of the card and cannot be shared to help another player in need. Community protection cards, however, require more resources, corresponding to the equivalent of three individual protection cards, but the cost can be shared among the players. The advantage is that less community protection cards are needed because they can be used efficiently by all characters within the sector facing a hazardous event. Once a hazardous event is taking place, players can decide to use their individual or community protection card to avoid (part of) the impacts. Once used, the card is no longer available to the players.

\subsection{Game outcome}

At the end of each year, the game master invites all the actors of the game to discuss the development of the island and the need to make joint decisions to develop the island or protect the entire community against hazards. Community protection cards can be acquired during this discussion. If a new strategy not defined within the Hazagora guidelines is voted for, the game master decides on the price to implement it on the board game. This allows the players to test, experience, and discuss new management ideas (see results section).

The game ends after a minimum of 5 years, which enables the players to experience a large suite of different hazardous events and explore and refine different mitigation strategies. They can also experience the same type of hazardous event several times. At the end of the game, the resilience of the community is evaluated using a resilience index that is calculated for each individual character and at the community level (Eq. 1). The number of living families with a permanent shelter and an access to natural resources, the number of infrastructures which are still in use on the board game and the amount of individual or community protection cards allow the players to gain capacity points. Those points are then divided by the vulnerability points that a player gets from the number of homeless, killed during the game, or without access to resources families, and the number of infrastructures that have been destroyed during the game. In addition, to evaluate the resilience level reached by the community, the resilience index is also used to rank the players and to generate discussion after the game. Strategies used by the players are then reviewed to explain why a player has a higher index outcome than another one.

Resilience index $=\frac{\text { capacity points }}{1+\text { vulnerability points }}$.

\section{Game implementation and tests}

A total of nine game sessions (75 players in total) have been organized in different countries (Belgium, Comoros Islands, Democratic Republic of Congo, and Tanzania) (Table 1). The African countries correspond to places where education and/or research projects regarding geohazards were already being led by the authors. The profiles of the players, aged 16 to 61 , were varied, involving groups of students (secondary and university), citizens, junior university staff, and stakeholders with different academic backgrounds and experience with hazardous events (Fig. 5). As the game was played in active volcano-tectonic regions, the majority of the African players had been confronted at least once with a hazardous phenomenon illustrated by the game, whereas European players usually had no experience with such event. The progress of each game session was recorded using a digital voice recorder and pictures were taken to illustrate the development of the families and infrastructures established on the board game at the end of each year and after each hazardous event. In addition, an observer, different from the game master, took notes to document the remarks and strategies adopted by the players.

In order to assess whether the learning objectives of the game were met, a short questionnaire was distributed before starting the game to define the profile of the players, their relation with hazardous events and their knowledge on the factors influencing disasters. At the end of the game, a second questionnaire to evaluate the players' opinion of the game and their knowledge of the factors influencing disasters was completed. The same set of statements, related to the factors influencing disasters, was proposed in both surveys but in a different order to avoid automatic answering. The player was asked to express his level of agreement with each statement 


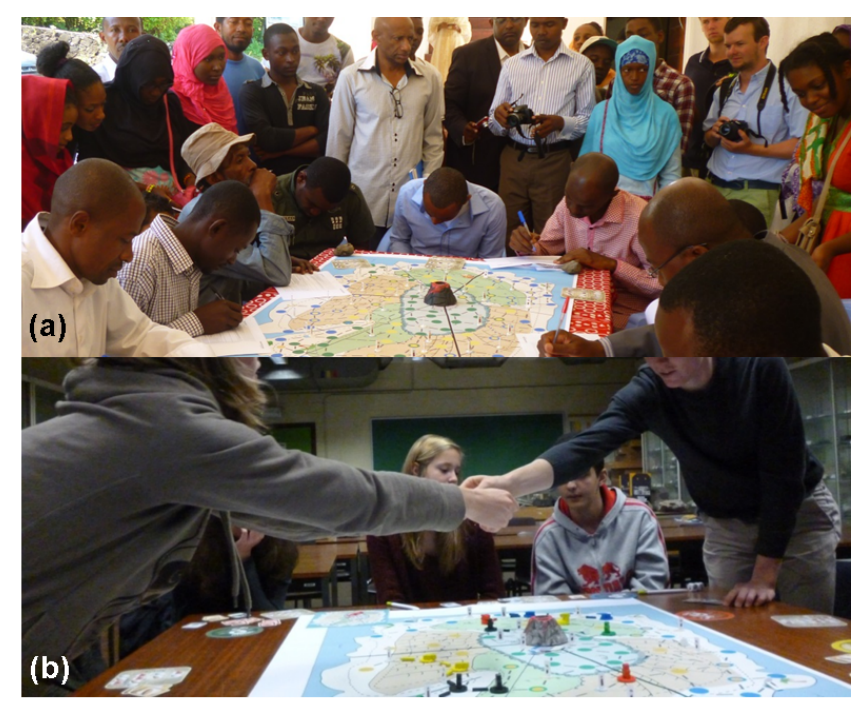

Figure 5. (a) Game session organized with citizens in Moroni (Comoros Islands). (b) Interaction among Belgian students to develop a resilient community.

using a five-level Likert scale. Statements with expected negative and positive answers were mixed. The evolution of answers determined the impact of the game in terms of insights gained on geohazardous phenomena and the role of livelihood strategies and access to natural resources in controlling the vulnerability profile of households and communities.

\section{Analysis of game outcomes}

\subsection{The strategies}

The different game sessions allowed observation of the development of different strategies of resilience. Not all strategies were adopted in each game session but a combination of some of them was systematically observed. No significant correlation between age, background, and experience with strategy could be made. However, these factors influence the decisions made by the players during the game. It also seems that strategies adopted during the game are influenced by personal desire to take risk or not, are mostly intermediary to the extremes strategies described below, and are changing during the game.

\subsubsection{Fast-growth fatalist versus protectionist strategies}

Throughout the sessions we observed two main adopted strategies, which we refer to as fast-growth fatalist and protectionist.

Fast-growth fatalist strategies are based on the player's assumption that he or she will be spared from geohazards and/or that the best way to survive potential impacts is by rapidly developing a large set of families. The player spends all resources to develop new families and limited or no protection cards are collected. No savings are built or planning is made to overcome a hazardous event or sustain daily life during a calm period. The player tends to have a lot of families to sustain. When impacted by a hazardous phenomenon, or when loosing access to resources due to road destruction, the player can no longer sustain all families, resulting in death or the need to request help from other players.

Contrarily, protectionist strategies focus on risk reduction strategies and resilient development. A player adopting such a strategy develops his or her families slowly and saves resources. Several complementary protection cards are collected. Families have therefore a higher chance of surviving a hazardous event and infrastructures are more adapted to resist it. Considering the recurrence of certain hazardous phenomena, an upgrade of the dwelling from a hut to a house allows the protectionist player to make sure the estate properties will withstand impacts from tsunamis and ash falls. He or she can further make a house resistant to earthquakes using the proper adaptation card. In addition to the basic Hazagora rules, some players sensitive to risk reduction suggested diversifying their activities to increase income and cope with the livelihood-targeting impacts. For example, a fisherman living along the coast may want to earn a second income from the upper slope of the island (lumberjack) such that when the fisherman does not receive income due to a tsunami, he or she will still receive resources from a livelihood which is not affected by the hazardous event.

\subsubsection{Spatial development of settlements}

Players may take account of space in different ways. The location of the initial two families is of major importance. The player might decide to concentrate his or her initial and subsequent dwellings. Doing so, the player clusters assets geographically and might face higher impacts once a hazardous phenomenon strikes that area. Alternatively, the player might decide to spread his or her development across the island, increasing the chance to be impacted by several hazardous events but each with more limited impacts.

Access of dwellings to water wells and food markets is taken into account by most players, at the start or during the game, because this saves resources.

Players sensitive to the spatial aspect of hazard distribution are usually also in favor of community initiatives regarding land use planning. Some players inquired about the availability of information about high-risk locations and whether the possibility existed to (re-)locate their families to safe places and therefore have a more resilient community. Although this is not directly foreseen in Hazagora, such remarks highlight that the game makes players more aware of the need for land use planning and spatial risk assessment. These comments were used as a basis for discussing risk management strategies during the game. 


\subsubsection{Cooperative and community strategies}

No instructions are given at the beginning of the game regarding the possibilities and modes of interaction among the players. Therefore, players usually start playing individually. Some players quickly understand the benefits of working as a community though. Players with diversified or monopolistic resource incomes develop economic strategies, trading their resources against those from other players to increase their total wealth (Fig. 5b).

Other cooperative strategies were developed, especially to support characters impacted by specific hazardous events. Donating resources or hosting homeless families of other characters in non-occupied dwellings, for free or in exchange for resources, were observed in several game sessions.

From a community perspective, it appeared generally difficult for all the characters to decide upon, and implement, community strategies. This arises from the fact that players experience different situations in terms of hazardous event impact and resource availability and develop different perceptions and strategies regarding hazards: the ones pleading for community support often being unable to invest much resources and vice versa. During some sessions, the players decided to collect taxes to be invested in community infrastructures, protection systems, or insurance. The most common community strategy is to either pool resources to be redistributed to hazardous event victims or buy community protection cards. These strategies are often implemented after several game years and are difficult to sustain throughout the years due to lack of resources of some players. Examples of infrastructures built as a community during the game sessions include a developed road network to connect all the dwellings to water wells and food markets and refugee camps to shelter people that have been affected by a hazardous event for a defined period.

\subsubsection{Impact of the strategies on the index of resilience}

Looking at the resilience index evolution for a selected game session (Fig. 6), one can see the extreme variance among players. The lumberjack adopted a fast-growth fatalist strategy but has been, in this example, spared. His fast development and his access to resources allowed this character to reach a high index of resilience even though he did not implement additional protection strategies. The tour guide has been repeatedly affected by geohazardous events. In year 2 , he lost one hut and one family due to ash fall (intensity three). In year 4, a lava flow burned three of his huts and covered four of his streets because his infrastructures were clustered in one sector of the island. Families could evacuate thanks to a mitigation card. Due to poor savings, poor access to resources, and little protection strategies, the tour guide kept a low resilience index throughout the game. A small improvement is observed at the end of the game thanks to the generosity of a player to shelter, for free, one homeless

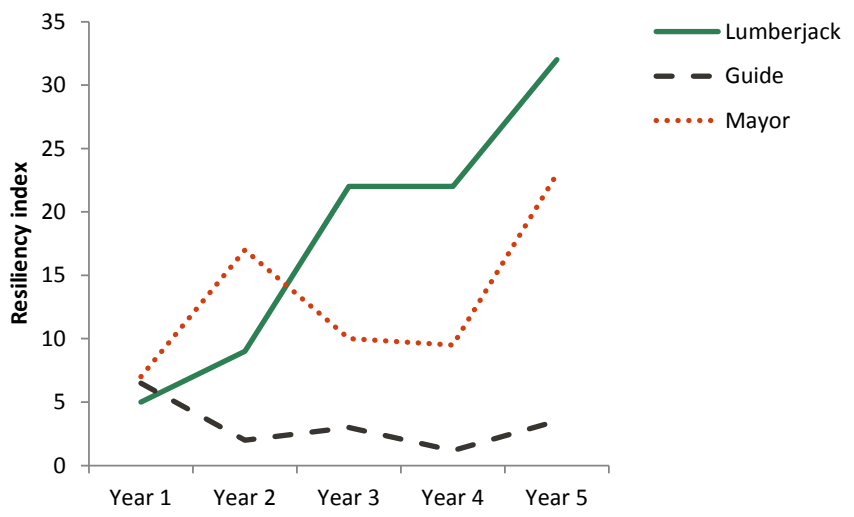

Figure 6. Example of the evolution of the resilience index for fastgrowth fatalist players not affected (lumberjack) and affected (tour guide) by geohazardous events during the game and for a protectionist player (mayor) affected but well prepared.

family of the tour guide. The mayor, in this game session, can be considered as representative of a protectionist player. The development of his community is progressive to ensure a good access to resources for all his families. Even though the mayor was affected in year 3 by a tsunami (intensity one), his savings allowed him to recover from it within 2 years. Cooperation to build a collective road network with another player also influenced his recovery. In the end, however, the resilience index for the mayor is lower than for the lumberjack, who did not experience any hazard.

\subsection{Disaster comprehension}

The survey results demonstrate that, before starting the game, the players already proved to have a moderate to good understanding of most concepts about disasters (Fig. 7). The trend of the answers given by the players at the beginning of the game corresponds to the expectations. Based on the expected answers, it is observed that, overall, $41 \%$ give the same answers before and after the game, $31 \%$ of the players give improved answers after the game, and $28 \%$ give diminished answers. As specified in Fig. 7, and considering the whole population of answers, a statistically significant improvement is observed regarding the players' understanding of the importance of land use spatial planning, community strategies, and home adaptation to develop a resilient community. When asked whether settlement location is mainly controlled by the will to avoid hazards, players initially answer negatively but seem to agree more with this statement after the game. For the rest of the statements, no statistically significant improvement is achieved, although the evolution in answers before and after the game follows the expected trend.

Figure 7 further shows that differences in the significance of the change in the answers provided before and after the game are observed for African and European players. After 


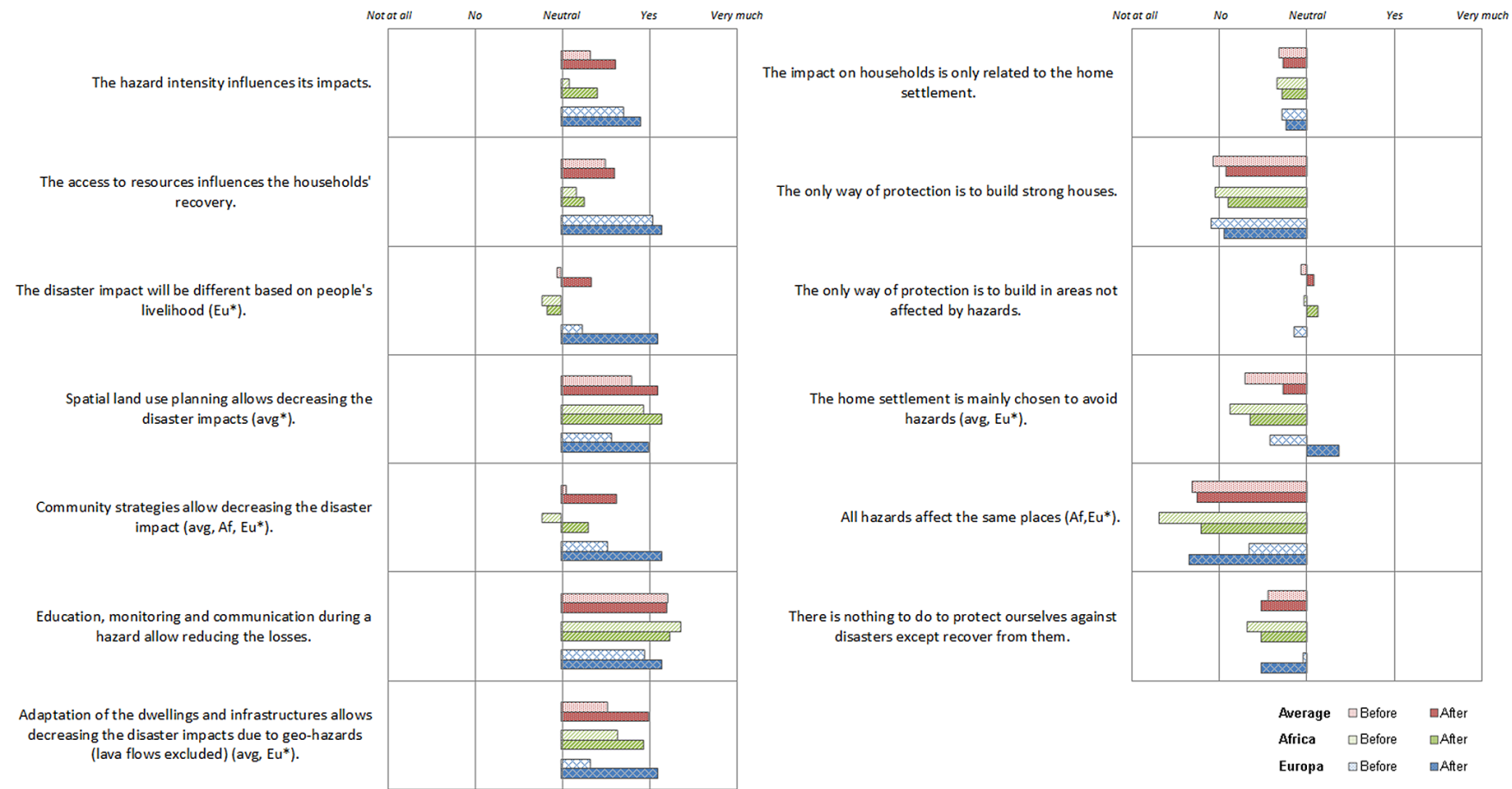

Figure 7. Evolution of the players' $(n=56)$ understanding of the different factors controlling the impact of a disaster before and after the game. Avg* indicates the evolution is significantly different on average $(p<0.05)$; Eu* indicates the evolution is significantly different for European players $(p<0.05)$; $\mathrm{Af}^{*}$ means the evolution is significantly different for African players $(p<0.05)$.

the game, both sets of players are more convinced about the importance of community strategies to reduce the impact of a disaster. Regarding the spatial variation of exposure to hazards, a contrasted evolution is observed in the two groups of players. African players are less in agreement with the statement that all hazardous phenomena affect the same places while European players are more convinced. European players also definitively improve their knowledge about the role of livelihood and infrastructure adaptations on decreasing the disasters impacts. Europeans also change their opinion regarding the statement that home settlement is mainly chosen to avoid hazards. Their consideration of the spatial distribution of hazards shows a significant positive evolution.

Based on the answers given to an open question of the survey, it is observed that players realize the benefit of sharing, investing, and helping each other by stating that working as a community can be considered as a DRR strategy. They also indicate the need for a better understanding of their environment to make thoughtful choices concerning land use planning and dwellings settlement.

\subsection{Players' impressions}

\subsubsection{Hazagora as a game}

According to the players, Hazagora is a fun game to play (Fig. 8). In the questionnaire, people stated that they would recommend the game to others. Some people suggested that the game should be "taught in secondary schools", "available to university staff members so that they can use it to teach students", and "given to the stakeholders to be used during discussions on national policy". According to some players (Fig. 8), the game rules are "the blueprint of real situations", which make it easier to understand the different steps of the game. European students can less easily relate the processes simulated by the game to their personal experience. However, some people suggested making the game more complex by taking into account the loss of fauna and flora or by incorporating more livelihood diversity. The flexibility of the game, enabling players to define their own strategies, is highly appreciated (Fig. 8). Finally, the tempo of the game is considered reasonable by the players.

\subsubsection{Hazagora as a tool for raising awareness on risk and disaster risk reduction strategies}

Players indicated that they receive enough scientific information throughout the game to have a better understanding of the physical mechanisms of hazards and their impacts on human properties and livelihood, with a clear focus on the latter (Fig. 8). They also state that Hazagora allows them to generate discussion in the group and collect information that may help them in developing mitigation plans in their personal or professional life. 


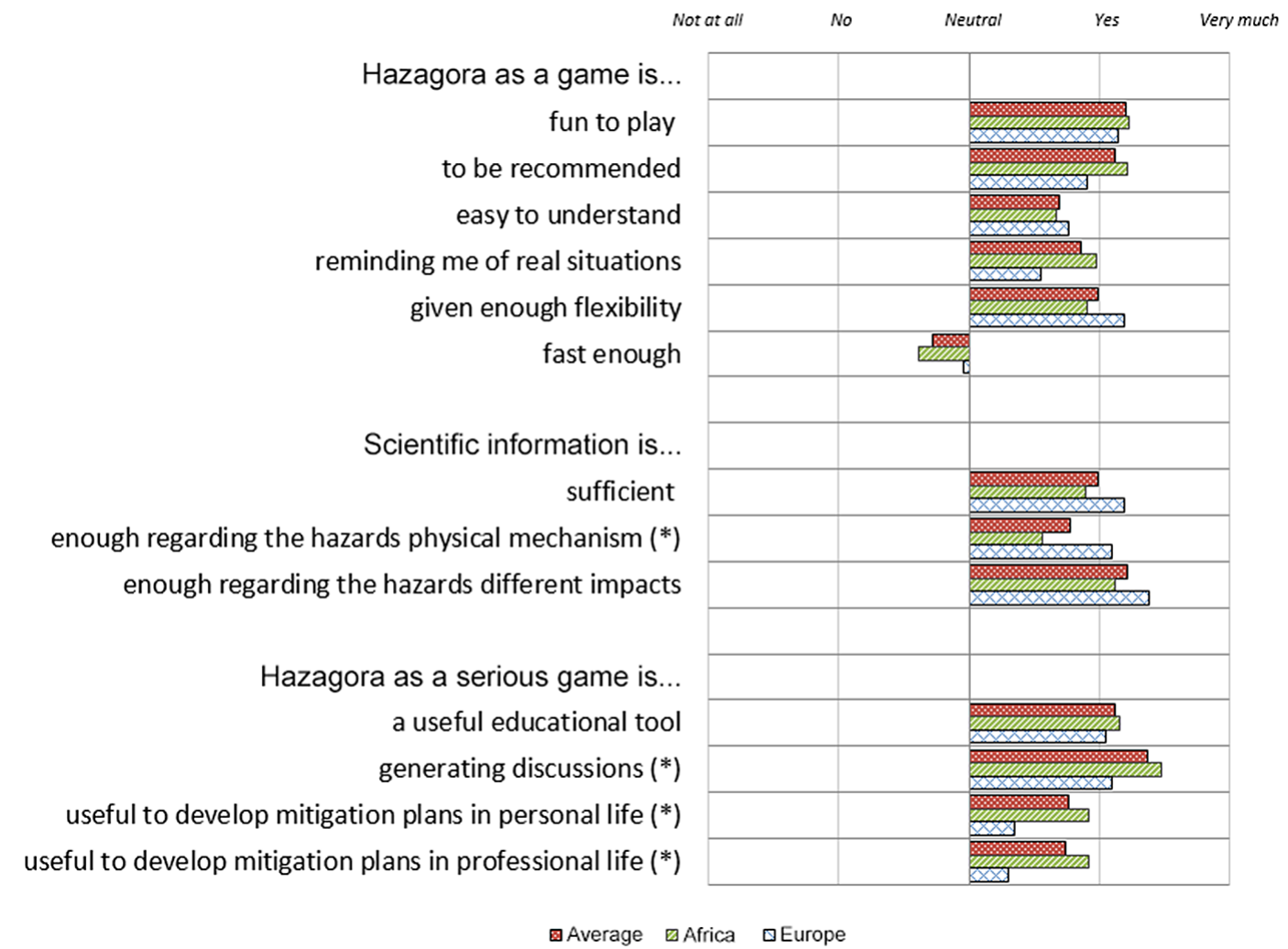

Figure 8. Appreciation of the game by the players $(n=75) .\left(^{*}\right)$ Results are significantly different between European and African players $(p<0.05)$.

A distinction, however, has to be made between the evaluation of the game by African and European players due to differences in life experiences and geological situations (Fig. 8). Where African players highlight the usefulness of the game to develop mitigation plans at a personal and a professional level, European players mostly draw attention to the scientific information conveyed by the game.

\section{Discussion}

\subsection{The strategies}

Comparisons could be made between development and DRR strategies implemented by the players and case studies of human communities confronted with disasters as described in the literature (Wisner et al., 2003). We here limit ourselves to a conceptual interpretation of the Hazagora strategies based on an analogy with a theory from ecology. The fast-growth fatalist and protectionist strategies developed during the surveyed sessions are comparable to the $r$ and $K$ strategies described in ecology for the establishment and development of species in nature.

The $r$ strategy is adopted by species living in a disturbed or newly created environment (Brown and Lomolino, 1998). These species are pre-adapted to colonize such environment thanks to their broad ecological tolerances and the fact that species adopting $r$ strategies have a large number of offspring at an early age (Brown and Lomolino, 1998; Parry, 1981). All the resources are spent for reproduction. Generation time is short mainly because of lack of parental care (Parry, 1981). This strategy can be compared to the fastgrowth fatalist strategy adopted by some Hazagora players. In a hazardous environment, players rapidly develop their families. All the resources are spent on their development without adopting DRR strategies. Those players gamble that they will be spared hazardous phenomena and evaluate the relative impacts of a hazardous event to be lower on an extensive community, despite the higher chance of incurring fatalities due to hazardous event impacts.

In nature, species adopting the $K$ strategy live in a more stable environment which is approaching its carrying capacity. They are therefore more adapted to efficiently use the limited resources (Brown and Lomolino, 1998). $K$ strategy species have a delayed reproduction with a limited number of offspring but of higher quality (Brown and Lomolino, 1998; Parry, 1981). Small amounts of resources are spent on reproduction but the life expectancy is longer thanks to parental care. Selection is due to resource shortage (Parry, 1981). Hazagora players adopting protectionist strategies during the game are comparable to the $\mathrm{K}$ strategy species. They aim at 
an efficient and sustainable management of their resources in order to develop themselves progressively. Savings are made and a large diversity of protection cards is collected to allow families to overcome disasters. Diversification of the income is also proposed by the players to protect themselves as multiple income source is an effective resilience strategy (Mavhura et al., 2013). In extreme situations, families will be sacrificed mainly due to lack of resources.

All fast-growth fatalist, protectionist, spatial, individual, or collective strategies described above were observed once or repetitively during the surveyed sessions but their implementation depends on various factors. Real life experience of hazardous events and impacts experienced during the game influences the players' strategies. It has been observed that these players usually adopt more protectionist strategies with a good access to resources. Observations also show that the strategy of a player changes during the game. Even if a player chooses a specific strategy during the game, he or she usually ends it with an extreme fast-growth fatalist strategy. At the end of the game, players have nothing to lose and invest all their savings to develop. Although it is initially stated that the cooperative goal of the game is to reach a resilient community as a whole, each player might favor the development of their own character, thus influencing their decisions. In addition, power relationships and social skills also seem to influence the group decisions. The game attributes a leadership position to the mayor during the discussions. This character is often caricatured and suffers sometimes from exclusion. In particular, African players project on the mayor their lack of trust regarding the authorities of their own country. Of course, Hazagora does not represent a real political system and the associated power relationships, but these observations highlight that the trust and cohesion between stakeholders and population are essential in the decision process. Experience shows that the personality of the player is influential. Charismatic or talkative players will more easily be able to impose their strategy even if it does not contribute to the community objective, whereas shyer players might not be able to defend their arguments. Game sessions with existing group cohesion were more animated. Hazagora thus helps develop important social and negotiation skills.

\subsection{Hazagora as a game}

Hazagora has been developed with the aim to encourage colearning through players' interactions and was therefore designed as a board game. In our view, the discussions among people who would not sit down together or otherwise interact when using traditional teaching methods lead to a better sharing of knowledge and experience. Besides, in several countries where the game has been tested, internet connection and computer facilities are limited and a board game thus appeared an appropriate tool. However, is the game attractive and are the objectives met?
The appreciation of a game is something highly personal and players have different standards for what they are looking for. However, some ingredients are important to make a game attractive: (1) it has to be playful and nourish the desire to play it again (Annetta et al., 2014; Castella et al., 2005; Turkay and Adinolf, 2012); (2) the rules have to be coherent to the target audience and should be easy to understand (i.e., rules should have a logic similar to reality) (Dieleman and Huisingh, 2006; Souchère et al., 2010); (3) players need tension, have to be surprised, and be challenged without having to wait too long (Martin et al., 2011; Turkay and Adinolf, 2012); (4) the appearance of the game has to be appealing and should help the player to relate the game to real situations, since it is a player's first impression of the game (Martin et al., 2011).

Based on the survey, Hazagora appears to be positively evaluated on each of these different characteristics. The game is appreciated by the players, who would generally recommend it to others. The rules are easy to understand, even though African players required more time before fully understanding the game structure, as board games are less part of their culture. The alarm defining when a hazardous event happens generates some tension and introduces an element of surprise to the players. Because hazardous events are implemented on the board game, players are challenged to protect their families and belongings. Discussions that occur during the game slow down the players who want to pursue the development of their families and protection measures. Discussions are, however, essential as it is during these moments that knowledge and experience are shared, community actions are debated, and information is formalized by the game master. The drawback is that one game session takes at least $3 \mathrm{~h}$ in order for the players to experience sufficient hazardous situations and test DRR strategies to fully benefit from the game learning potential. Finally, the design and the quality of the game illustrations also help the players to appreciate the game. Specific attention was paid to create characters and visuals that are generic enough in order for players from different cultures to be able to connect to them (i.e., faces and livelihoods of characters).

\subsection{Hazagora as a tool for raising awareness on risk and disaster risk reduction strategies}

Several games have already been developed to raise awareness about one or several hazards and reduce their impact (e.g., Stop Disasters!, UN/ISDR, 2004; Disaster Hero, FEMA, n.d.; Riskland, UN/ISDR, 2004; Save Natalie!, International Decade for Natural Disaster Reduction, n.d.; Paré pas paré, Croix-rouge française, 2012; Volcanic Disaster, Volcano Video Productions, n.d.). Most of these DRR games target preferentially a young audience as children are known to be a vulnerable group (Elangovan and Kasi, 2015; UN/ISDR, n.d.). Once educated about DRR, children are considered to contribute more than adults to a change 
towards a more proactive preventive approach to disasters (Johnson et al., 2014). These games can be played as a board or card game or online. Online games allow giving systematic scientific information to the players but limit the interaction among them. It also must be noted that these games do not emphasize the aspects of livelihoods and access to resources. They are more focused on basic protective measures for hazards. For its part, Volcanic Disaster (Volcano Video Productions, n.d.) introduces the players to forecasting techniques and to a sampling of the world volcanoes and their associated hazards.

Hazagora targets an older audience, as we argue that serious gaming is a useful communication mode for teenagers and adults, especially for addressing complex processes and for favoring interaction. The game has been tested with groups of different age, culture, knowledge, and experience. The players' feedback on the game was always positive.

Information about the mechanisms of hazards and their impacts on infrastructures, natural resources, and livelihood is illustrated during the game. African players suggested that the scientific information provided during the game is sufficient but their appreciation for this aspect is always lower than that of the European players. This may be due to a difference in initial knowledge. They have more experience with geohazardous phenomena and that is why they want to learn even more about the hazardous events they might face in their daily life, resulting in higher expectations. This highlights the need to adapt the focus of the game, especially the discussions and the explanations provided by the game master, to the background of the players.

Hazagora aims at illustrating the four elements of the risk equation: hazards, spatial exposure, vulnerability, and DRR capacities. Throughout the game, importance is specifically given to the influence of livelihoods, access to resources, and contrasted DRR strategies, as these concepts are typically less familiar to the players. Even though not all answers to the questionnaires demonstrate a significant improvement in knowledge and understanding about disasters and how to reduce the risks involved, the game generally contributes to increasing the players' awareness regarding different factors influencing risk and the need to interact to test new strategies. Results showed more significant improvement among European players. However, the game generated more intense discussions about contrasted DRR strategies among African players. This can be explained by the fact that those players are better acquainted with at least one of the hazardous events described in Hazagora, they were mostly older than the European players, and they realize more often that the discussions of new strategies to implement in the board game can be useful to develop their own mitigation plans at a personal or at a professional level. These results highlight that Hazagora has the potential to be used for different but complementary purposes, focusing on educating about geohazards and risk concepts, or as a basis to generate discussion on identifying and testing possible DRR strategies, depending on the target audience.

For some participants, the surveys indicated an evolution opposite to the expectations. This can partially be attributed to the way some of the statements were formulated and to the difficulty of isolating one factor from the other ones. Answers to the questionnaires also depend on the specificity of the game session. Indeed, each game session is unique: hazardous events experienced, discussions, and extent of the impacts on the board game will differ, which may result in more attention being given to one or another disaster factor. The game master has to ensure that discussions address all elements influencing the disaster and that enough time is allocated to summarize the main message of the game in the end. In order to be sure that players receive all the information needed, information sheets about the hazards and appropriated DRR strategies that can be developed during the game are distributed to each player after the game.

\subsection{Limitations and prospects of the game}

One of the key limitations of games is the need for significant simplification and generalization. This ensures that a game is fun to play and that the rules are understandable. In terms of hazards, only four geohazards are addressed by Hazagora. In order to maximize the learning outcome of the game and let players experience different hazardous phenomena of contrasted magnitude, it is advisable to implement adaptations such that an event of a given magnitude that already has been experienced in the game does not take place again in the following years. The hazardous event spatial extent is also simplified, neglecting for example the topographic control on lava flow and tsunami distribution, as well as the variation of ash fallout or earthquake intensity with distance from the source. Although hazardous phenomenon intensities are differentiated, the game does not represent a realistic magnitude - frequency distribution nor does it consider the spatial variation of the probability of hazardous event occurrence. Impacts of the hazardous phenomena on the island are also limited to the elements present on the board game. Only infrastructural, financial and human losses are therefore taken into account. Cultural, economic, environmental, and political factors influencing the livelihood strategies, the access to resources and the decision process are not represented. The livelihood profiles of the characters are also imposed and do not evolve during the game.

The game is also very generic in terms of geographic setting and character profiles. This has the advantage that it can be played with participants of different age, culture, and knowledge about natural risks and risk management. However it might prevent some players relating directly to the game as the specific hazard and risk conditions of their environment they are familiar with are not represented. These issues of simplification and generalization can partially be addressed by the game master by providing information and 
examples relevant to the players and by inviting the players to discuss and possibly adapt the game rules. As already mentioned above, more detailed information on mechanisms of hazards, spatial distribution, and impacts are provided to each player in an info leaflet at the end of the game. In the future, modified versions of the game in terms of geographic setting, as well as resource distribution or accessibility, could be implemented to fit the needs of a specific region and target audience. Finally, implementation of additional or alternative hazardous events, such as landslides or flooding, could be considered if topographic characteristics of the landscape are properly simulated on the board game. Rules would stay more or less the same but a new set of impacts provoked by the events would have to be defined.

Another limitation of the game, especially for improving DRR awareness, is the time required to play it. The need to dedicate several hours to a game session is clearly a limitation for integrating of the game into a teaching program and it may be more suitable as an extracurricular activity. A balance has to be found between the play and the informative aspect of the game. Because of the diversity of the game objectives, it may be beneficial to play the game several times. During a first session, time could be dedicated to explain the rules and to discover all information needed to get a better understanding of geohazards. In a second session, the game could then focus on highlighting the factors controlling the disasters, while a third session could focus more on the interaction among the players as well as on developing and testing DRR strategies.

A final limitation of the game is the need for a game master highly knowledgeable in the addressed topics to lead the game and guide the players' discussions. The game sessions were so far led by one of the co-authors, but to multiply the impact of the game there is a need in the future to train teachers or other science communication actors as game masters. A detailed game master guideline document is already available to describe the game procedure, key points to be highlighted during the discussions, and some examples of recent disasters.

Based on the experience of the Hazagora sessions and the results of the survey, we do not argue that this learning method can replace more traditional and structured teaching methods but rather that it serves as a useful way to activate participants and introduce them to the complex concepts of disasters.

\section{Conclusions}

In this paper we presented a new approach using a serious game to educate a broad audience about geohazards, disasters, and DRR strategies, including secondary school students, citizens, and risk managers.

Hazagora demonstrated to be a successful board game that players find fun to play, informative, and stimulating. De- spite the necessary simplifications, the game provides a good representation of the main elements of natural disasters. The game challenges the players to protect their families against unforeseen geohazardous events. The game format facilitates the learning process, enhances discussions among players, and encourages them to test new DRR strategies.

Hazagora has been tested with young and older player groups from different backgrounds, residing in Europe and Africa. The survey demonstrates that most players already had some understanding about disasters before the game but that their knowledge tended to improve after the game. The objectives achieved depend on the targeted public. For people with little knowledge about geohazards or disasters, Hazagora mainly manages to improve their understanding of geohazards and the factors controlling a disaster. For people confronted in their daily life with geohazardous events, the game is mainly able to generate discussions which may help in developing risk management strategies. The game impact is expected to improve if it is played several times by the same players, who could then improve their resilience strategies. Experience shows that players not used to playing board games need more time to understand the game rules. In the future, new versions of the game may be implemented to adapt the setup to specific places, hazards, or targeted audiences.

Hazagora contributes to make players more aware of (1) mechanisms of hazards, their intensity, spatial extent, and impacts on infrastructures, natural resources, and livelihood; (2) the elements influencing the vulnerability of a community with respect to hazardous phenomena; and (3) potential strategies that can be applied to make a community more resilient. Indeed, new DRR strategies can be implemented in the game which allow players to test various risk management approaches without having to deal with the real consequences of their decisions. The game is therefore a new relevant alternative among the many tools and methods that have already been proposed for raising awareness on disaster risk reduction.

Acknowledgements. We are extremely grateful to Ilja Van Braeckel for developing the visual material of the game, to Benoît Smets for providing some of the pictures, and to Jef Van Laer and Anja Decoster for their supportive comments on earlier versions of the game. We thank all the participants of the game sessions of Hazagora game for their enthusiasm and insightful discussions. We thank Jan Lindsay and Rui Prada for their review of a preliminary version of this study which greatly helped to improve the manuscript. S. Mossoux acknowledges the financial support of the VUB Doctoral School of Natural Sciences and M. Van Molle for her fieldwork to the Comoros Islands. The Hazagora game was developed in the framework of the $\mathrm{PhD}$ research of S. Mossoux on volcanic risks of the Karthala volcano, the South Initiative project "Increasing teaching and research capacities on geological processes, resources and hazard management in the Northern Tanzania Volcanic Zone" funded by the Flemish Interuniversity Council for Development Cooperation (VLIR-UOS), and the GeoRisCA 
project "Geo-risk in Central Africa: integrating multi-hazards and vulnerability to support risk management" funded by the Belgian Science Policy (BELSPO project SD/RI/02A).

Edited by: B. D. Malamud

Reviewed by: J. Lindsay and R. Prada

\section{References}

Annetta, L., Lamb, R., Minogue, J., Folta, E., Holmes, S., Vallett, D., and Cheng, R.: Safe science classrooms: teacher training through serious educational games, Inf. Sci. (Ny)., 264, 61-74, doi:10.1016/j.ins.2013.10.028, 2014.

Boyle, E. A., MacArthur, E. W., Connolly, T. M., Hainey, T., Manea, M., Kärki, A., and van Rosmalen, P.: A narrative literature review of games, animations and simulations to teach research methods and statistics, Comput. Educ., 74, 1-14, doi:10.1016/j.compedu.2014.01.004, 2014.

Brown, J. H. and Lomolino, M. V.: Biogeography, 2nd ed., Sinauer Associates, Sunderland, Massachusetts, 1998.

Castella, J., Trung, T. and Boissau, S.: Participatory simulation of land-use changes in the Northern mountains of Vietnam: the combined use of an agent-based model, a role-playing game, and a Geographic Infromation System, Ecol. Soc., 10, 27, available at: http://www.ecologyandsociety.org/vol10/iss1/art27/ (last access: 20 January 2015), 2005.

Croix-rouge française: Paré pas paré, available from: http://piroi. croix-rouge.fr/-051-pare-pas-pare (last access: 10 March 2015), 2012.

Dieleman, H. and Huisingh, D.: Games by which to learn and teach about sustainable development: exploring the relevance of games and experiential learning for sustainability, J. Clean. Prod., 14, 837-847, doi:10.1016/j.jclepro.2005.11.031, 2006.

Elangovan, A. R. and Kasi, S.: Psychosocial disaster preparedness for school children by teachers, Int. J. Disaster Risk Reduct., 12, 119-124, doi:10.1016/j.ijdrr.2014.12.007, 2015.

FEMA: Disaster hero, available from: http://www.disasterhero. com/ (last access: 10 March 2015), n.d.

Guha-Sapir, D., Hoyois, P., and Below, R.: Annual disaster statistical review 2013 - the numbers and trends, Brussels, 2014.

International Decade for Natural Disaster Reduction: Learning about natural disasters- games and projects for you and your friends, available from: http://www.mona.uwi.edu/cardin/ virtual_library/docs/1248/1248.pdf (last access: 10 March 2015), n.d.

Johnson, V. A., Ronan, K. R., Johnston, D. M., and Peace, R.: Evaluations of disaster education programs for children: A methodological review, Int. J. Disaster Risk Reduct., 9, 107-123, doi:10.1016/j.ijdrr.2014.04.001, 2014.

Lamarque, P., Artaux, A., Barnaud, C., Dobremez, L., Nettier, B., and Lavorel, S.: Taking into account farmers' decision making to map fine-scale land management adaptation to climate and socio-economic scenarios, Landsc. Urban Plan., 119, 147-157, doi:10.1016/j.landurbplan.2013.07.012, 2013.
Martin, G., Felten, B., and Duru, M.: Forage rummy: A game to support the participatory design of adapted livestock systems, Environ. Model. Softw., 26, 1442-1453, doi:10.1016/j.envsoft.2011.08.013, 2011.

Mavhura, E., Manyena, S. B., Collins, A. E., and Manatsa, D.: Indigenous knowledge, coping strategies and resilience to floods in Muzarabani, Zimbabwe, Int. J. Disaster Risk Reduct., 5, 38-48, doi:10.1016/j.ijdrr.2013.07.001, 2013.

Montessori, M.: The human tendencies and Montessori Education, Association, Amsterdam, 1966.

Parry, G. D.: The meanings of r- and K-selection, Oecologia, 48, 260-264, 1981.

Pereira, G., Prada, R. and Paiva, A.: Disaster prevention social awareness - the Stop Disasters! case study in Proceedings of VSGAMES - 6th International Conference on Games and Virtual Worlds for Serious Applications, Msida, Malta, 2014.

Smith, K.: Environmental hazards - assessing risk and reducing disaster, edited by: Routledge, O., 2013.

Souchère, V., Millair, L., Echeverria, J., Bousquet, F., Le Page, C., and Etienne, M.: Co-constructing with stakeholders a roleplaying game to initiate collective management of erosive runoff risks at the watershed scale, Environ. Model. Softw., 25, 13591370, doi:10.1016/j.envsoft.2009.03.002, 2010.

Susi, T., Johannesson, M., and Backlund, P.: Serious Games - An Overview, Skövde, 2007.

Turkay, S. and Adinolf, S.: What do players (think they) learn in games?, Procedia - Soc. Behav. Sci., 46, 3345-3349, doi:10.1016/j.sbspro.2012.06.064, 2012.

UN/ISDR: Let's learn to prevent disasters - educational kit and riskland game, available from: http://www.unisdr.org/we/inform/ publications/2114 (last access: 10 March 2015), 2004.

UN/ISDR: Terminology, available from: http://www.unisdr.org/we/ inform/terminology\#letter-r (last access: 10 March 2015), 2007.

UN/ISDR: Stop disasters! - A disaster simulation game from the UN/ISDR, available from: http://www.stopdisastersgame.org/en/ home.html (last access: 10 March 2015a), n.d.

UN/ISDR: What is Disaster Risk Reduction?, available from: http: //www.unisdr.org/who-we-are/what-is-drr,

United Nations: International Strategy for Disaster Reduction Hyogo Framework for Action 2005-2015: Building the Resilience of Nations, World Conf. Disaster Reduct., 25, 2005.

United Nations: Sendai Framework for Disaster Risk Reduction 2015-2030, Sendai., 2015.

Video Productions Volcano: Volcanic disaster - the eruption prediction game, available from: http://www.volcanicdisastergame. com/index.html (last access: 30 September 2015), n.d.

Wisner, B., Blaikie, P., Cannon, T., and Davis, I.: Framework and theory, in At Risk: natural hazards, people's vulnerability and disasters, 1-134, Routledge, London, 2003. 